\title{
Hi-tech down on the farm
}

\section{Michael E. Moncaster}

Computers and Electronics in Agriculture. Editor-in-chief J.R. Lambert. Elsevier. 4/yr. Dfl. 236.

Over the past decade electronics and computing have become vitally important to agricultural research, development and production. Until recently, however, there was no journal dedicated to this area of application. Computers and Electronics in Agriculture aims to fill the gap.

Launched in October 1985, its policy is to cover any application of computers or electronics to instrumentation, control or management of agricultural processes, activities, equipment, enterprises or systems. Modelling, computer software and information processing are included where relevant to agricultural management, and also robotics for agricultural production. Agriculture is interpreted broadly to include forestry and veterinary medicine, as well as all aspects of crop and livestock production.

In the first four issues, published over a period of 17 months, papers covered a wide range of applications, even extending to the fishing industry. Robotics was one of the few subjects not touched upon. Although the journal is intended as an international forum, authors were from five countries only, and all but six of the 30 papers and notes were from North America. Europe was represented by British contributors only.

Editorial policy is to include original papers on scientific work, reviews of particular topics, technical notes on (for example) circuits, systems or programs, scientific discussions, letters commenting on published papers, guest editorials, book reviews and notices of international meetings. In practice, half of the papers are eight to ten pages long $(3,000-4,000$ words), and each issue contains on average about six papers, one of which extends to 17 or 18 pages. Five technical notes of five to eight pages have been included, as well as one review paper of 25 pages - on semiconductor device technology and digital system design - and two book reviews. As yet no letters, guest editorials, scientific discussions or notices of international meetings have appeared.

The scientific quality of the papers is high; no doubt refereeing by the appropriately qualified and diverse editorial board with representatives from ten countries helps. To what extent this slows down publication is not clear, but on average eight months have elapsed between acceptance and publication. The quality of production is similarly high; layout, printing, illlustrations, paper and binding are excellent. With about 500 words on a page $16 \mathrm{~cm}$ by $24 \mathrm{~cm}$, legibility is no problem.

At a subscription of $\$ 75$ for the first four issues, this journal represents good value for a specialized publication. Its high quality in all respects and the success with which its aims are being met outweigh some shortcomings in the amount and type of information presented and in the publication delays evident in the first year or so. Because of its unique coverage of

\section{Thrilled to the marrow}

\section{Elizabeth Jones}

Bone Marrow Transplantation. Editors John Goldman and Robert Peter Gale. Macmillan, London. 6/yr. UK £75; elsewhere $£ 100$.

Bone Marrow Transplantation is a journal which provides a unique overview of both the experimental and the clinical aspects of allogeneic and autologous bone marrow transplantation (BMT). To say it has an international flavour would be an understatement; the editors and assistant editors are representatives of six countries, and the editorial review board of over 70 individuals is drawn from 18 countries. Understandably, the journal has already attracted papers of a high scientific standard.

The journal is published quarterly at present but will appear bimonthly in 1988 . Each volume usually contains an editorial, review articles, case reports, a large

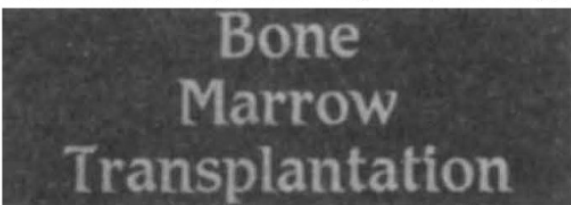

number of first-class papers (which are usually published within six months of submission) and announcements of future meetings. So far, however, there has been only a regrettably limited amount of correspondence.

The review articles cover a wide variety of topics such as the use of circulating stem cell allografts in BMT, the use of cyclosporin to prevent graft-versus-host disease (GvHD), analysis of BMT in man during the past 18 years, and the role of BMT in thalassaemia and in multiple myeloma. The problems of using unrelated donors in BMT are covered and future trends in gene therapy are discussed. With gene therapy there is the exciting prospect of inserting normal genes into bone marrow stem cells before autologous BMT of corrected marrow for the treatment of a particularly important area, its chances of survival are good, provided that the quality can be maintained. Although the subscription has increased to $\$ 100$ for Vol. 2, it must remain on the essential reading list for all those involved in the application of computers and electronics to agriculture.

Michael E. Moncaster is Head of the Information Engineering Division, Agricultural and Food Research Council Institute of Engineering Research, Silsoe, Bedfordshire MK45 4HS, UK.

haematological malignancies (leukaemia), enzyme deficiencies (severe combined immunodeficiency disease) and haemoglobinopathies (sickle cell disease, thalassaemia).

The donor of choice for an allogeneic BMT is an HLA-identical sibling, or a one-haplotype-matched family member, but HLA-matched unrelated donors are being increasingly used. The first editorial in Vol. 1 enumerates four areas in which BMT survival must be improved and most of the papers cover these areas. First, donor selection must be improved, particularly in transplants using HLAmismatched family donors and unrelated HLA-identical donors, by using more sensitive matching of donor and recipient. The importance of matching for Class III antigens $(\mathrm{C} 2, \mathrm{C} 4, \mathrm{Bf})$, for minor histocompatibility antigens, and the use of cDNA probes direct against the HLA genes are mentioned. Given the importance of the HLA system in BMT, there is a notable lack of papers in this area in the journal.

Secondly, improved conditioning regimes are needed and the relevance of TBI doses, busulphan and cyclophosphamide are discussed in the journal. Third, GvHD occurs in 45 per cent of HLA-matched recipients and in 75 per cent of one-haplotype-matched recipients. Techniques to reduce GvHD are discussed, such as in vitro treatment of marrow with soy bean agglutinin, monoclonal antibodies (Campath-1, IgM), albumen gradient sedimentation, E rosetting and treatment of patients with cyclosporin, methotrexate, and psoralen with ultraviolet light. Lastly, treatment of infection in BMT patients with toxoplasmosis, herpes viruses, cytomegalovirus and varicella zoster is adequately covered.

The articles and reviews are presented in a clear, concise fashion. This, together with the high-quality figures and illustrations, makes Bone Marrow Transplantation understandable both to specialists in the field and to the less expert. The latter in particular should be encouraged to read this journal.

Elizabeth Jones is a Lecturer in the Section of Human Genetics, Institute of Cancer Research, Fulham Road, London SW3 6JJ, UK. 